\title{
Azobispyrazole family as photoswitches combining (near-)quantitative bidirectional isomerization and widely tunable thermal half-lives from hours to years
}

Yixin He, Zhichun Shangguan, Zhao-Yang Zhang, ${ }^{*}$ Mingchen Xie, Chunyang Yu, and Tao Li* School of Chemistry and Chemical Engineering, Frontiers Science Center for Transformative Molecules, Shanghai Key Laboratory of Electrical Insulation and Thermal Aging, Shanghai Jiao Tong University, Shanghai 200240, China.

*E-mail: litao1983@sjtu.edu.cn; zy_zhang@sjtu.edu.cn

\begin{abstract}
Azobenzenes are classical molecular photoswitches that have received widespread application. In recent endeavors of molecular design, replacing one or both phenyl rings by heteroaromatic ones is emerging as a strategy to expand the molecular diversity and to access improved photoswitch properties. However, the currently available heteroaryl azo switches generally show limitations on $E \leftrightarrows Z$ photoisomerization yields and/or $Z$-isomer stability. Here we report a family of azobispyrazoles as new photoswitches, which combine (near-)quantitative bidirectional photoconversions and widely tunable $Z$-isomer thermal halflives $\left(t_{1 / 2}\right)$ from hours to years. A visible-light-activated photoswitch is also obtained. Systematic experimental and theoretical investigations reveal the different geometric and electronic structures of azobispyrazoles from those of phenylazopyrazoles, overcoming the conflict existing in the latter between effective photoconversion and $Z$-isomer stability. Our work shows the great potential of azobispyrazoles in developing photoresponsive systems and can inspire the rational design of new photoswitches making use of bis-heteroaryl azo architecture.
\end{abstract}

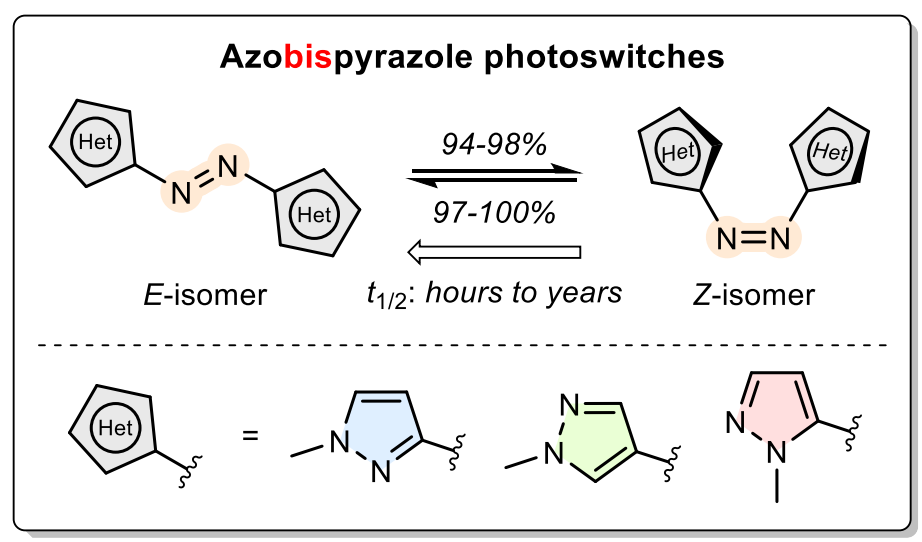




\section{Introduction}

Molecular photoswitches, which can be reversibly interconverted between different states by light irradiations, have inspired intensive efforts in developing light-responsive systems for diverse applications. ${ }^{1-9}$ Azobenzenes are the most widely used photoswitches and play dominating roles in many areas, such as photomechanical actuation of soft materials, ${ }^{10,11}$ photopharmacological modulation of physiological functions, ${ }^{12,13}$ and photochemical solar thermal energy storage. ${ }^{14-16}$ For azo photoswitches, probably the foremost factor determining their quality is the $E \leftrightarrows Z$ photoisomerization yields in both directions. Quantitative bidirectionality is highly desirable, since incomplete photoconversion in any direction will compromise the capability of photoswitching. Another essential property is the thermal stability of metastable isomer ( $Z$-form, in general), which spontaneously relaxes back to the thermodynamically stable state. The suitable thermal back-isomerization kinetics, represented by halflife $t_{1 / 2}$ (values are at $25{ }^{\circ} \mathrm{C}$ hereinafter, if not specified), depends on the application of interest. For example, $t_{1 / 2}$ ranging from seconds to hours can match the timescales of various biological events, ${ }^{17,18}$ while ultralong $t_{1 / 2}$ of months to years are advantageous for information and energy storage. ${ }^{14,19}$

Azobenzene ( $\mathrm{Ph}-\mathrm{N}=\mathrm{N}-\mathrm{Ph})$ itself is a highly adaptable molecular architecture because of numerous structural modification possibilities. Since the discovery of azobenzene photoisomerization in $1937,{ }^{20}$ introducing substituent groups to phenyl rings has produced a plethora of azobenzene derivatives. ${ }^{21,22}$ In recent endeavors of molecular design, replacing one or both phenyl rings by heteroaromatic ones has attracted increasing attention. ${ }^{23}$ The diversity of heterocycles and their distinct nature from benzene provide tremendous opportunities to regulate the performance of azo switches. Six-membered rings such as pyridine $e^{24,25}$ and pyrimidine $e^{26,27}$ afforded heteroaryl azo switches in which coordination interaction and hydrogen bonding could be made use of. Significantly, mono-heteroaryl azo molecules ( $\mathrm{Ph}-\mathrm{N}=\mathrm{N}-\mathrm{Het})$ based on five-membered rings (imidazole, ${ }^{28,29}$ pyrazole, ${ }^{30,31}$ pyrrole, ${ }^{30,31}$ thiophene, $, 32,33$ isoxazole,${ }^{34}$ etc.) showed some unusual features. Herges group ${ }^{29}$ and Fuchter group ${ }^{30}$ reported that the $Z$-isomer of phenylazoimidazoles and phenylazopyrazoles could adopt a T-shaped conformation (where phenyl ring was orthogonal to azo-heterocycle part), which is not accessible by azobenzenes. Herges et al ${ }^{29}$ disclosed that such $\mathrm{T}$ conformation could enlarge the difference in conjugation degree between $E$ and $Z$ isomers and thus their $\pi-\pi^{*}$ absorption bands were well separated, enabling complete $E \rightarrow Z$ photoisomerizations. A later systematic study by Fuchter et $\mathrm{al}^{31}$ revealed that $\mathrm{T}$ conformation was crucial for high $Z$-isomer stability ( $t_{1 / 2}$ up to 1000 days) but detrimental to $Z \rightarrow E$ photoconversion (due to the weakness of $Z$-isomer $n-\pi^{*}$ absorption). Structural modifications could improve the photoconversion, which, however, shortened their $Z$-isomer $t_{1 / 2}$ to months or days. ${ }^{31,35-37}$ Phenylazothiophenes could also display T-shaped $Z$-isomers, accompanied with low $Z \rightarrow E$ photoisomerization yields in general, while their $t_{1 / 2}\left(20^{\circ} \mathrm{C}\right)$ were at the timescale of hours or less. ${ }^{32,33}$ Azo switches bearing a benzoheterocycle such as quinoline, ${ }^{27}$ indole, ${ }^{38}$ indazole, ${ }^{39}$ and purine ${ }^{40}$ were also reported. Their extended $\pi$ system led to red-shifted $\pi-\pi^{*}$ 
absorption and generally accelerated back relaxation with $t_{1 / 2}$ from nanoseconds to days. In despite of these important progress on mono-heteroaryl azo switches, a great challenge remains on how to achieve quantitative bidirectional photoconversions and, at the same time, tune their $t_{1 / 2}$ from short to very long.

Bis-heteroaryl azo architecture (Het-N=N-Het) can further expand the molecular diversity and offer a more progressive way in tailoring the geometric and electronic structures, which, however, has not received sufficient attention. Fuchter group ${ }^{41}$ designed and synthesized azobis(2-imidazole), a visible light azo switch with $90 \%$ and $\sim 100 \%$ conversions for $E \rightarrow Z$ and $Z \rightarrow E$ directions, respectively. Its $Z$ isomer adopted a twisted conformation and $t_{1 / 2}$ was only $1.6 \mathrm{~s}$. Very recently, Beves et $\mathrm{al}^{42}$ studied some azobisbenzazoles bearing benzimidazoles, benzoxazole or benzothiazoles, which showed $73-84 \% E \rightarrow Z$ conversions under visible light. Notably, azobisbenzimidazole obtained a $t_{1 / 2}$ of $520 \mathrm{~s}$, which was among the longest $t_{1 / 2}$ of visible light azoheteroarene switches. ${ }^{42}$ Azobisthiophenes were shown to be different with phenylazothiophenes in that its $Z$-isomers were also twisted and $t_{1 / 2}$ were up to 38 days $\left(22^{\circ} \mathrm{C}\right)$, yet their photoisomerization yields remain to be determined. ${ }^{43}$ By combining electron-rich (thienyl)pyrrole/bithiophene and electron-deficient (benzo)thiazole, a series of push-pull bis-heteroaryl azo switches were constructed, which were responsive to visible light and their $Z$-isomer $t_{1 / 2}$ ranged from milliseconds to seconds. ${ }^{44-47}$ In view of the very limited types of bis-heteroaryl azo switches reported so far and their limitations on bidirectional photoconversion and/or Z-isomer stability, the potential of Het$\mathrm{N}=\mathrm{N}-\mathrm{Het}$ architecture is far from exploited, calling for the development of new molecular systems.

Here we present a family of azobispyrazoles as new photoswitches, as shown in Figure 1, all of which show excellent bidirectional photoconversions and their $Z$-isomer $t_{1 / 2}$ can be broadly tuned from hours to years by changing the linking position between azo group and pyrazole rings. The azobispyrazole motif reforms the geometric and electronic structure relative to phenylazopyrazoles, thereby overcoming the conflict between effective photoconversion and $Z$-isomer stability existing in the latter. Therefore, our work demonstrates the great potential of bis-heteroaryl architecture in molecular design, performance improvement, and broad applications of azo photoswitches.

\section{Results and discussion}

\section{Molecular Design and Synthesis}

By bridging two pyrazole rings with an azo group at $\mathrm{C} 3, \mathrm{C} 4$, or $\mathrm{C} 5$ positions, a family of six azobispyrazoles can be formulated, including three symmetrical members (3-3, 4-4, and 5-5) and three asymmetrical members (3-4, 3-5, and 4-5), as shown in Figure 1. Because of the distinct nature of the three kinds of carbons on pyrazole ring, variations in linkage pattern can regulate the molecular geometry and electronic structure of the whole system, which is expected to have a significant effect on their photoswitch properties. 


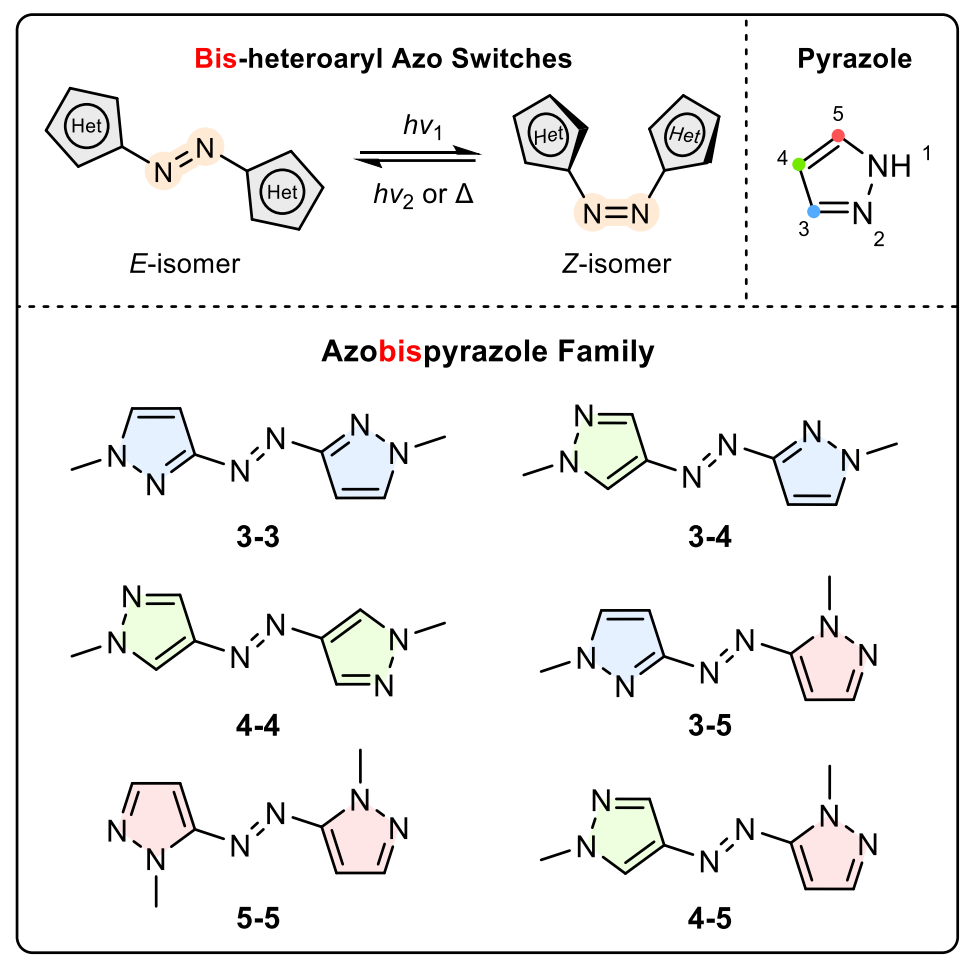

Figure 1. Molecular design of azobispyrazole family. ( $N$-methylation is necessary to prevent the azohydrazone tautomerization that dramatically accelerates thermal $Z \rightarrow E$ isomerization.)

Synthesis routes of azobispyrazole family were shown in Scheme 1. In previous studies, phenylazopyrazoles containing 3,5-dimethylated 4-pyrazole were synthesized by diazo couplings between phenylamine and acetylacetone with subsequent ring formation. ${ }^{30,48}$ Inspired by this method, we first attempted to prepare our azobispyrazoles containing methyl-free 4-pyrazole (3-4, 4-4, and 4-5) using pyrazolylamines and malonaldehyde that was generated from in situ hydrolysis. However, the yield of diazo coupling step was uncontrollable (5 50\% in different trials) since the malonaldehyde was prone to polymerize in solution during the hydrolytic process. Therefore, we employed malonaldehyde sodium salt (MDA-Na), which can be isolated in pure solids and stable over weeks in dry atmosphere. ${ }^{49}$ In this way, pyrazolyl hydrazone intermediates (3-HM, 4-HM and 3(5)-HM) were obtained in reproducible yields of $\sim 50 \%$. Further reactions with methylhydrazine sulfate constructed the 4-pyrazole rings at the other side of azobispyrazoles with product yields of $65-80 \%$. The other three members $\mathbf{3 - 3}, \mathbf{3 - 5}$, and $\mathbf{5 - 5}$ were prepared in one pot through oxidation coupling of $1 \mathrm{H}$-pyrazol-3(5)-amine $\mathrm{e}^{50,51}$ and subsequent $\mathrm{N}$ methylation at two selectable positions, benefitting from the tautomerism of $1 H$-pyrazole. 3-3 and 5-5 were also obtained by electrochemistry in previous work $^{52,53}$. The single-crystal structure of all the six members have been determined by X-ray crystallographic analysis (see Section 4 in the Supporting Information, SI). 
Scheme 1. Synthesis routes of azobispyrazoles.

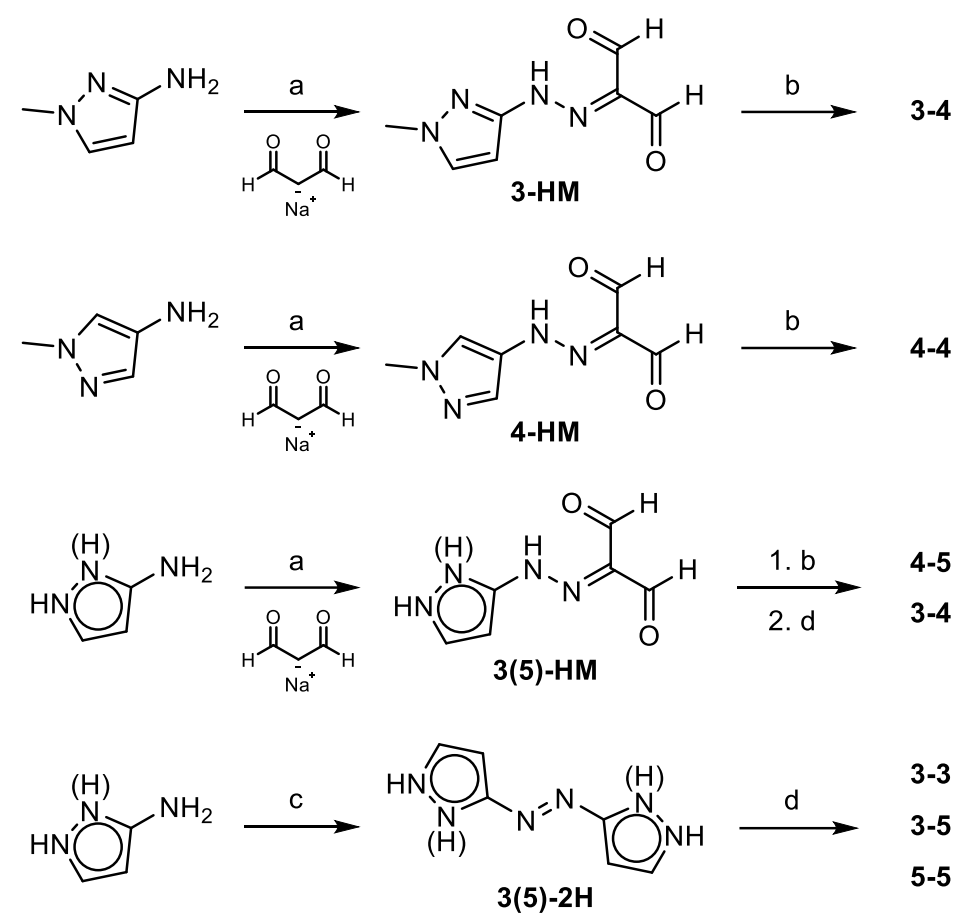

Reagent and conditions. (a) $\mathrm{AcOH}$, concentrated $\mathrm{HCl}$, aqueous $\mathrm{NaNO}_{2}, 0^{\circ} \mathrm{C}$, then aqueous $\mathrm{KOAc}$, MDANa, 0-5 ${ }^{\circ} \mathrm{C}, 40-54 \%$; (b) Methylhydrazine sulfate, $\mathrm{KOAc}$, EtOH, refluxed, 65-80\%; (c) $\mathrm{MnO}_{2}, \mathrm{CHCl}_{3}$, $80{ }^{\circ} \mathrm{C}, 25 \%$; (d) $\mathrm{CH}_{3} \mathrm{I}_{1} \mathrm{Cs}_{2} \mathrm{CO}_{3}$, DMF, room temperature, $83-85 \%$.

\section{Photoisomerization}

The photoisomerization properties of azobispyrazoles were studied via UV-Vis absorption spectroscopy. As shown in Figure 2, the $E$-isomers exhibited strong $\pi-\pi^{*}$ absorption bands in $300-400$ $\mathrm{nm}$ region $\left(\varepsilon_{\max }=18-27 \times 10^{3} \mathrm{M}^{-1} \mathrm{~cm}^{-1}\right)$, and the peak position varied with the linkage pattern. As shown in Table 1 and Figure 2, the $\pi-\pi^{*} \lambda_{\max }$ red-shifted from $325-327 \mathrm{~nm} \mathrm{(3-3,3-4}$ and 4-4) to $342 \mathrm{~nm}$ (3-5 and 4-5) and further to $356 \mathrm{~nm}(\mathbf{5 - 5})$. In all cases, irradiation of $E$-isomers at $\pi$ - $\pi^{*}$ bands using appropriate light source $(350 / 365 / 375 \mathrm{~nm})$ resulted in almost complete conversions (94-98\%) to Z-isomers (Table 1 and Figure 2), benefitting from the overwhelming absorbance of $E$ over $Z$ isomers at the excited wavelengths. These $Z$-isomers displayed more evident $\mathrm{n}-\pi^{*}$ absorption bands in visible region than $E$ isomers, and exciting the $n-\pi *$ transition at band tails by green light could induce quantitative backward isomerization for all azobispyrazole members. In contrast, the mono-pyrazolyl azo switches (phenylazopyrazoles), regardless of the linkage pattern, suffered from heavy overlapping of the $n-\pi^{*}$ bands between two isomers, which restricted the yield/efficiency of their $Z \rightarrow E$ photoisomerization, ${ }^{30,31}$ and thus structural modification by substitution at the phenyl/pyrazole ring was necessary to improve the performance. ${ }^{30,35-37}$ Moreover, 5-5 could be used as a bidirectionally visible-light-activated photoswitch, which provided $85 \% E \rightarrow Z$ and $\sim 100 \% Z \rightarrow E$ conversion by 405 and $555 \mathrm{~nm}$ light irradiations, respectively (Figure 2-inset). Quantum yields of $E \rightarrow Z\left(\pi-\pi^{*}\right.$ excitation) and $Z \rightarrow E$ (n- $\pi^{*}$ excitation) 
isomerizations were determined as $0.30-0.47$ and $0.45-0.77$, respectively, which were generally much higher than those of azobenzene $(0.10-0.15$ and $0.41-0.58) .{ }^{22}$ This manifests another advantage of Het$\mathrm{N}=\mathrm{N}-\mathrm{Het}$ over $\mathrm{Ph}-\mathrm{N}=\mathrm{N}-\mathrm{Ph}$ architecture.

Table 1. Spectroscopic data, photoisomerization yields, quantum yields $(\Phi)$, and thermal half-lives $\left(t_{1 / 2}\right)$ of azobispyrazole family.

\begin{tabular}{cccccccccc}
\hline & \multicolumn{2}{c}{$E$-isomer $^{a}$} & \multicolumn{2}{c}{$Z$-isomer $^{a}$} & \multicolumn{2}{c}{ Photoconversion $^{b}$} & \multicolumn{2}{c}{$\Phi^{g}$} & \multirow{2}{*}{$t_{1 / 2}{ }^{i}$} \\
\cline { 2 - 7 } & $\begin{array}{c}\pi-\pi^{*} \lambda_{\max } \\
(\mathrm{nm})\end{array}$ & $\begin{array}{c}\mathrm{n}-\pi^{*} \lambda_{\max } \\
(\mathrm{nm})\end{array}$ & $\begin{array}{c}\pi-\pi^{*} \lambda_{\max } \\
(\mathrm{nm})\end{array}$ & $\begin{array}{c}\mathrm{n}-\pi^{*} \lambda_{\max } \\
(\mathrm{nm})\end{array}$ & $\begin{array}{c}E \rightarrow Z \\
(\%)\end{array}$ & $\begin{array}{c}Z \rightarrow E \\
(\%)\end{array}$ & $\begin{array}{c}E \rightarrow Z \\
(\%)\end{array}$ & $\begin{array}{c}Z \rightarrow E \\
(\%)\end{array}$ & $(\mathrm{d})$ \\
\hline $\mathbf{4 - 4}$ & 327 & $\sim 395$ & 277 & 420 & $98^{c}$ & $99 / \sim 100^{f}$ & $42^{c}$ & $77^{h}$ & 681 \\
$\mathbf{3 - 4}$ & 326 & $\sim 394$ & 277 & 413 & $97^{c}$ & $97 / 99^{f}$ & $30^{c}$ & $45^{h}$ & 623 \\
$\mathbf{3 - 3}$ & 325 & 400 & 277 & 430 & $97^{c}$ & $98 / 99^{f}$ & $33^{c}$ & $61^{h}$ & 72 \\
$\mathbf{4 - 5}$ & 342 & - & 285 & 430 & $97^{d}$ & $98 / 99^{f}$ & $47^{d}$ & $71^{h}$ & 25 \\
$\mathbf{3 - 5}$ & 342 & $\sim 413$ & 295 & 440 & $97^{d}$ & $98 / 99^{f}$ & $45^{d}$ & $58^{h}$ & 6 \\
$\mathbf{5 - 5}$ & 356 & - & 323 & 451 & $94^{e}$ & $99 / \sim 100^{f}$ & $39^{d}$ & $49^{h}$ & 0.3 \\
\hline
\end{tabular}

${ }^{a}$ The $\lambda_{\max }$ were taken from UV-Vis absorption spectra measured in acetonitrile solution $\left(4 \times 10^{-5} \mathrm{M}\right) .{ }^{b}$ The isomer compositions were obtained through integrating the peak areas of ${ }^{1} \mathrm{H}$ NMR spectra measured in acetonitrile- $d_{3}$ solution, irradiated by ${ }^{c} 350 \mathrm{~nm},{ }^{d} 365 \mathrm{~nm},{ }^{e} 375 \mathrm{~nm},{ }^{f} 520 / 555 \mathrm{~nm}$ light (see Section 2.1 in SI). ${ }^{g}$ Measured in acetonitrile solution using ${ }^{c} 350 \mathrm{~nm},{ }^{d} 365 \mathrm{~nm}$ and ${ }^{h} 470 \mathrm{~nm}$ light excitation (see Section 2.3 in SI) ${ }^{i}$ Values at $25{ }^{\circ} \mathrm{C}$ in DMSO, extrapolated from the kinetics data at elevated temperatures using Arrhenius equation except that of 5-5 (see Section 3 in SI).
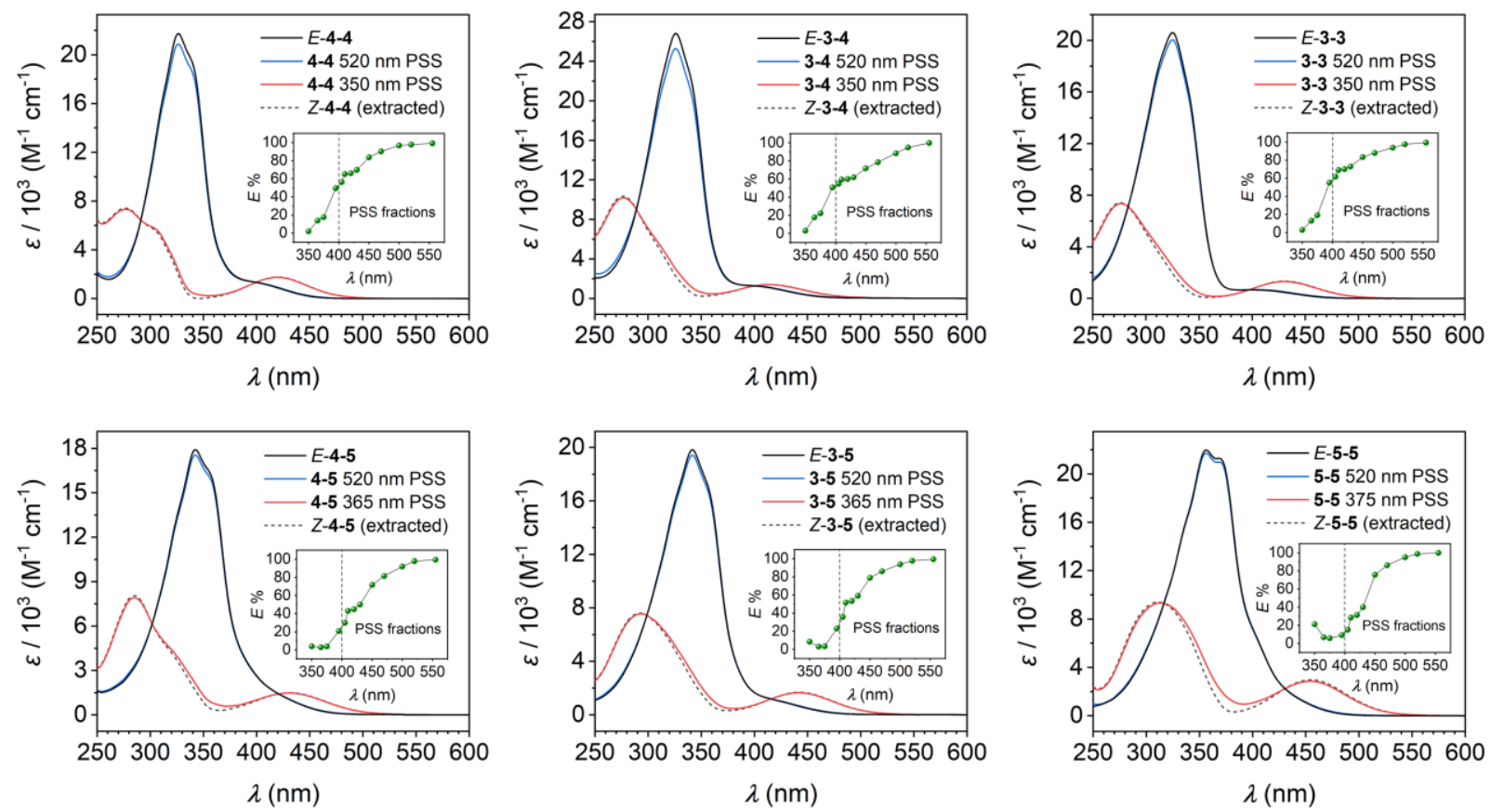

Figure 2. UV-Vis absorption spectra of azobispyrazoles in acetonitrile. Insets show $E$-isomer contents at $350-555 \mathrm{~nm}$ photostationary states (see their corresponding spectra in Figure S7). 
In order to reveal the relationship between molecular structures and electronic transition characteristics, density functional theory (DFT) and time-dependent DFT were performed for all possible conformers (see Section 5 in SI). For $E$-isomers, the $\pi-\pi^{*}$ absorption band ( $\mathrm{S}_{0} \rightarrow \mathrm{S}_{2}$ excitation) corresponded to HOMO-LUMO transition (Figure $3 \mathrm{a}$ ). The calculated $\lambda_{\max }$ agreed well with the experimental values, which red-shifted with the reduction of $\mathrm{H}-\mathrm{L}$ gaps. This reflected the dependence of $\pi$-conjugation degree on linkage pattern. According to the electron-donating conjugative effect from pyrrole-type $\mathrm{N}$ lone pair, the 5-pyrazole forms a "complete" conjugation pathway with azo group while that from 4- and 3-pyrazole is only "partial". ${ }^{31}$ As a result, the molecular architecture bearing more 5-pyrazole moiety showed larger $\pi$-conjugation extension in pyrazole-azo-pyrazole system, making the $\pi-\pi^{*} \lambda_{\max }$ follow the order of 5-5 > 3(4)-5 $>$ 3(4)-3(4). The $n-\pi^{*}$ band ( $\mathrm{S}_{0} \rightarrow \mathrm{S}_{1}$ excitation) of $E$-isomers corresponded to HOMO-1-LUMO transition (Figure 3a). It appeared that $n-\pi^{*}$ transitions require less excitation energies than $\pi$ - $\pi^{*}$ but with larger fundamental gaps (H-1-L gaps vs. H-L gaps). This discrepancy, which was also found in other azoheteroarenes, ${ }^{28,31}$ can be ascribed to the difference in exciton binding energies. ${ }^{54}$

a)

E-4-4 (2) FMO

Z-4-4 (2) FMO

LUMO
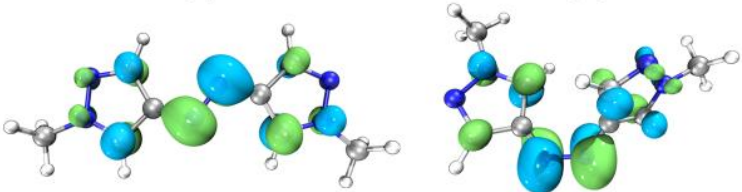

$-1.647 \mathrm{eV} \pi *$

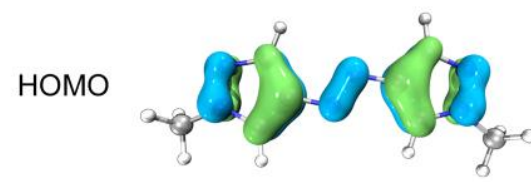

$-1.623 \mathrm{eV} \pi *$

$-6.064 \mathrm{eV} \pi$

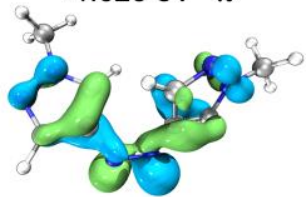

$-5.897 \mathrm{eV}$

HOMO-
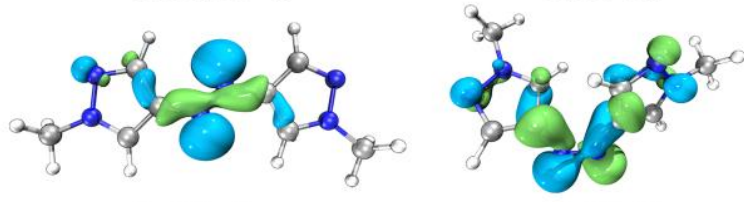

$-6.585 \mathrm{eV} \mathrm{n}$

$-6.934 \mathrm{eV}$

b)

Z-4-4 (2) NTO

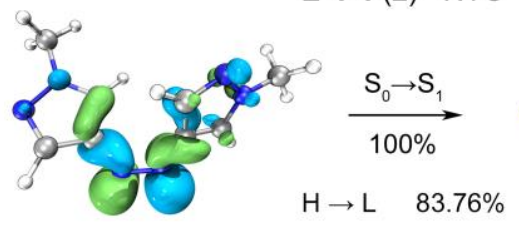

$\mathrm{n}$

$\mathrm{H}-1 \rightarrow \mathrm{L} \quad 15.13 \%$
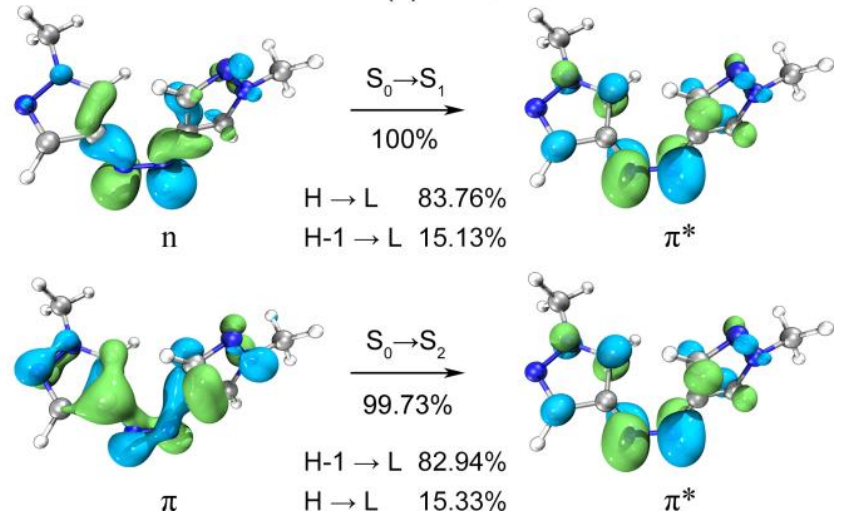

Figure 3. (a) Frontier molecular orbitals and (b) natural transition orbitals for the predominant conformers of 4-4 (isosurface value of 0.05). Results of the other molecules were illustrated in Figures S25-S30. 
3-3 (2) $60.42 \%$

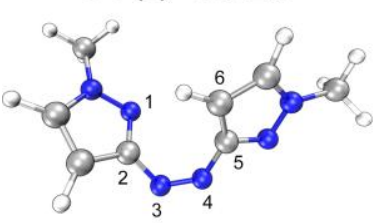

$\varphi(\mathrm{N} 1-\mathrm{C} 2-\mathrm{N} 3-\mathrm{N} 4)=53.9^{\circ}$

$\varphi(\mathrm{C} 2-\mathrm{N} 3-\mathrm{N} 4-\mathrm{C} 5)=9.8^{\circ}$

$\varphi\left(\right.$ N3-N4-C5-C6) $=18.6^{\circ}$
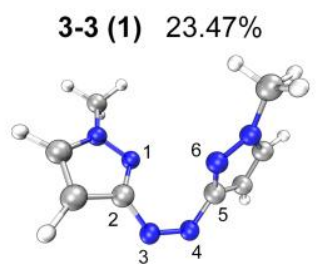

$\varphi\left(\right.$ N1-C2-N3-N4) $=39.2^{\circ}$

$\varphi(\mathrm{C} 2-\mathrm{N} 3-\mathrm{N} 4-\mathrm{C} 5)=12.0^{\circ}$

$\varphi\left(\right.$ N3-N4-C5-N6) $=39.2^{\circ}$
3-4 (3) $41.57 \%$

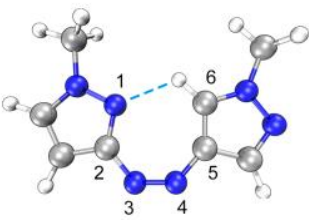

$\varphi(\mathrm{N} 1-\mathrm{C} 2-\mathrm{N} 3-\mathrm{N} 4)=0.0^{\circ}$

$\varphi(\mathrm{C} 2-\mathrm{N} 3-\mathrm{N} 4-\mathrm{C} 5)=0.0^{\circ}$

$\varphi\left(\right.$ N3-N4-C5-C6) $=0.0^{\circ}$

3-4 (4) $29.97 \%$

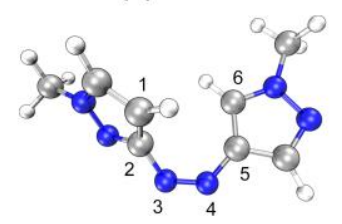

$\varphi(\mathrm{C} 1-\mathrm{C} 2-\mathrm{N} 3-\mathrm{N} 4)=44.5^{\circ}$

$\varphi(\mathrm{C} 2-\mathrm{N} 3-\mathrm{N} 4-\mathrm{C} 5)=9.8^{\circ}$

$\varphi\left(\right.$ N3-N4-C5-C6) $=20.3^{\circ}$
3-5 (4) $74.97 \%$

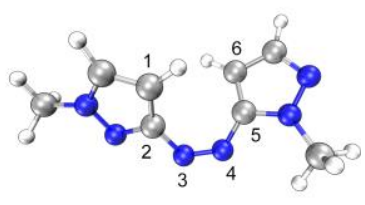

$\varphi\left(\right.$ C1-C2-N3-N4) $=25.6^{\circ}$

$\varphi(\mathrm{C} 2-\mathrm{N} 3-\mathrm{N} 4-\mathrm{C} 5)=11.2^{\circ}$

$\varphi\left(\right.$ N3-N4-C5-C6) $=34.7^{\circ}$

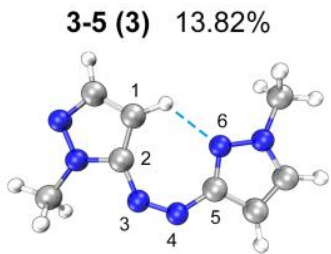

$\varphi(\mathrm{C} 1-\mathrm{C} 2-\mathrm{N} 3-\mathrm{N} 4)=0.0^{\circ}$

$\varphi(\mathrm{C} 2-\mathrm{N} 3-\mathrm{N} 4-\mathrm{C} 5)=0.0^{\circ}$

$\varphi\left(\right.$ N3-N4-C5-N6) $=0.0^{\circ}$

Figure 4. The geometrical structure of typical Z-conformers and their Boltzmann distribution (calculated in acetonitrile, see all conformations in Table S14 and Figure S23).

For $Z$-isomers, the frontier molecular orbital (FMO) theory could not well describe the nature of electronic excitations, since the frontier occupied molecular orbitals mixed $\mathrm{n}$ and $\pi$ composition and each transition was contributed by multiple sets of orbitals. Therefore, the natural transition orbital (NTO) analysis $^{55,56}$ was performed, and we found that the $\mathrm{S}_{0} \rightarrow \mathrm{S}_{1}$ and $\mathrm{S}_{0} \rightarrow \mathrm{S}_{2}$ excitations could be almost identified as $\mathrm{n}-\pi^{*}$ and $\pi-\pi^{*}$ transitions, respectively (Figure $3 b$ ).

The $E$-isomers of azobispyrazoles showed a planar conformation and their $n-\pi^{*}$ transitions were symmetry-forbidden with negligible oscillator strength $f(0.0000-0.0003)$. By contrast, the $Z$-isomers were generally twisted with two large CCNN dihedral angles as well as a small CNNC dihedral angle (Figures 4, S22 and S33). This broke the geometrical symmetry and remarkably increased $f$ to $0.02-0.08$ (Table S16). As a result, all $Z$-isomers showed strong $n-\pi^{*}$ absorbance against $E$-isomers, responsible for quantitative $Z \rightarrow E$ photoisomerizations.

Interestingly, a couple of planar conformers were found in Z-3-4 and Z-3-5, which were stabilized by an intramolecular $\mathrm{C}-\mathrm{H} \cdots \mathrm{N}$ hydrogen bond between the pyridine-type $\mathrm{N}$ atom on 3-pyrazole ring and a $\mathrm{C}-\mathrm{H}$ group on the other ring (Figure 4 and S23). These planar conformers showed small $f$ of 0.0020 0.0026 (Table S16). For Z-3-4, the two planar conformers accounted for 55\%, explaining its relatively low $n-\pi^{*}$ band, while the absorbance of $Z-3-5$ was of "normal" intensity because its sole planar conformer Z-3-5 (3) was of small distribution, as revealed by theoretical calculations (Table S14). Planar Z-isomer conformation were never observed in $\mathrm{Ph}-\mathrm{N}=\mathrm{N}-\mathrm{Ph}$ or $\mathrm{Ph}-\mathrm{N}=\mathrm{N}-\mathrm{Het}$ type molecules, but were also found in azobis(2-imidazole), ${ }^{41}$ its protonated product, ${ }^{41}$ and protonated azobis(benzothiazole) ${ }^{42}$ indicating that the steric hindrance associated with six-membered ring can be largely weakened by two five-membered rings. 


\section{Thermal $Z \rightarrow E$ Isomerization}

The thermal $Z \rightarrow E$ isomerization of azobispyrazoles followed first-order kinetics (see Section 3 in SI), and their $Z$-isomer $t_{1 / 2}$ at $25{ }^{\circ} \mathrm{C}$ were listed in Table 1 . Ultralong $t_{1 / 2}$ values of near 2 years were achieved by 4-4 and 3-4, making them rare azo switches possessing extraordinarily stable $Z$-isomers. ${ }^{30,57,58}$ The $t_{1 / 2}$ could be further regulated to months, weeks, days, and hours by adjusting the linkage pattern. Such a widely tunable $t_{1 / 2}$ could meet the kinetic requirements of a broad spectrum of photo-responsive systems. We could find that the Z-isomer stability did not rely on its geometrical structure, since the twisted geometry allowed a widely tunable $t_{1 / 2}$. This is in stark contrast with phenylazopyrazoles, for which the $\mathrm{T}$ and twisted shape dictates long and short $t_{1 / 2}$, respectively. ${ }^{30,31}$

As shown in Table 1 and Figure 5a, a clear trend between $Z$-isomer $t_{1 / 2}$ and bridging position was found: the 4-pyrazole unit favored long $t_{1 / 2}$ the most, followed by the 3 -pyrazole, and finally the 5-pyrazole; and $t_{1 / 2}$ took orders from the combination of the two units, i.e., 4-4 $>3-4>3-3>4-5>3-5>5-5$. The visible light switch 5-5 showed a $t_{1 / 2}$ of $7 \mathrm{~h}$, much higher than that of the other visible light bis-heteroaryl azo switches reported so far. ${ }^{41,42,44-47}$

In order to understand the thermal $Z \rightarrow E$ isomerization behavior of azobispyrazole family, we studied their potential energy curves, which indicated that the lowest energy pathway followed inversion mechanism (Figure 5b and Figure S31). Based on the inversion transition states (TSs), their free energy barriers $\Delta G^{\ddagger}$ (difference in Gibbs free energy between TS and $Z$-isomer, $G_{\mathrm{TS}}-G_{Z}$ ) were calculated (Table S17). As shown in Figure 5a, the $t_{1 / 2}$ increased with the rise of energy barriers, including theoretical $\Delta G^{\ddagger}$ and experimental activation energies $E_{\mathrm{a}}$, in line with the transition state theory. Since $G_{\mathrm{TS}}$ and $G_{Z}$ were influenced by intramolecular stabilizing/destabilizing interactions, the noncovalent interaction (NCI) analysis $^{56,59}$ of $Z$-isomers and TSs was performed. The results of their predominant conformers were shown in Figure 5c.

For the TSs of molecules with 5-pyrazole (4-5, 3-5 and 5-5), the bulky $\mathrm{N}$-methyl group on 5-pyrazole was ortho to the remaining azo-pyrazolyl part, enabling them to form dispersive interactions, while such stabilizing interactions were absent for the other three molecules (their $N$-methyl were away from azo groups). Therefore, the TS barriers were easier to overcome in the 5 -pyrazole series. For the $Z$-isomers of this series, the $\mathrm{N}$-methyl group on 5-pyrazole of 4-5 orientated towards the other pyrazole ring side; it gave rise to the largest dispersive surface that stabilized Z-4-5 the most, explaining its longest $t_{1 / 2}$ in this series. Moreover, the higher stability of Z-3-5 than Z-5-5 could be probably attributed to the relatively stronger stabilizing effect of intramolecular $\mathrm{C}-\mathrm{H} \cdots \mathrm{N}$ hydrogen bond in planar Z-3-5. 
a)

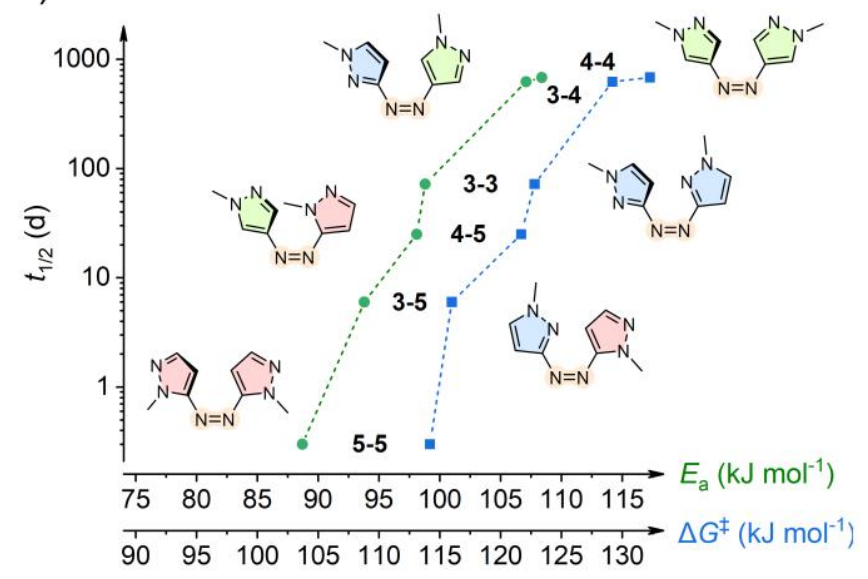

b)

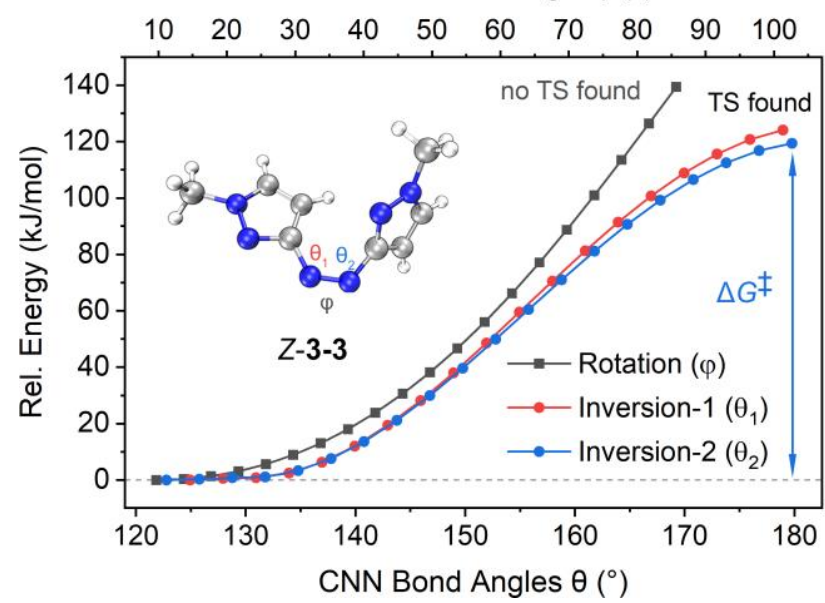

c)
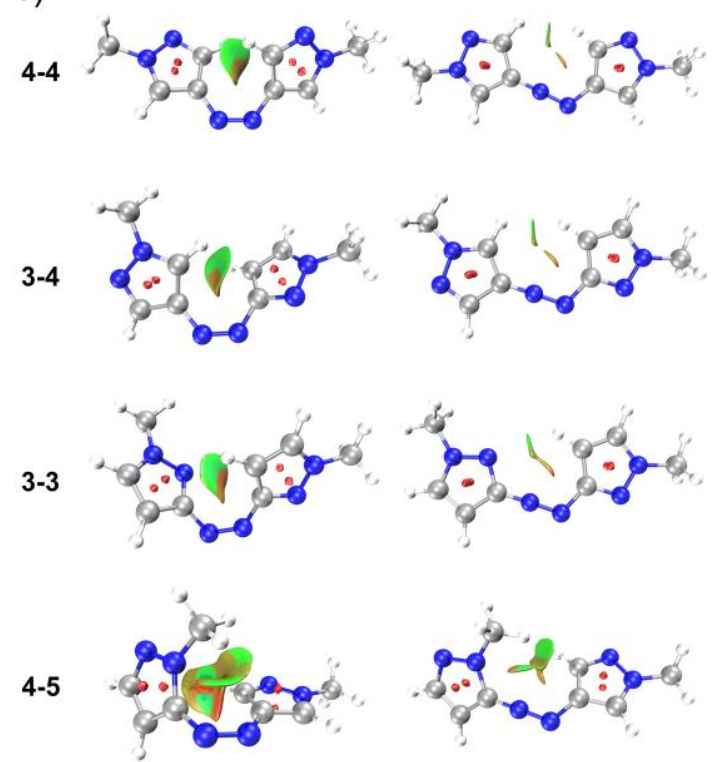

3-5
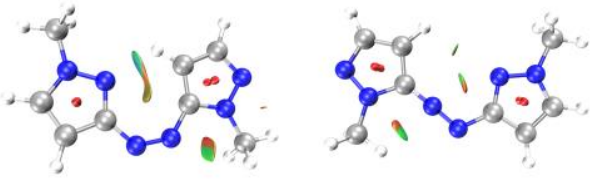

5-5

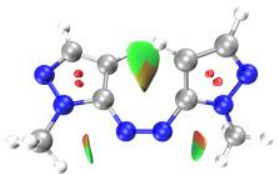

Z-isomers

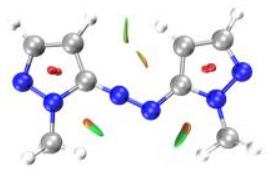

Transition States

Figure 5. (a) The relationship between thermal half-lives and energy barriers for azobispyrazoles (in DMSO). The activation energies $\left(E_{\mathrm{a}}\right)$ were calculated through Arrhenius plot based on experimental kinetics data (see Section 3 in SI), and the free energy barriers $\left(\Delta G^{\star}\right)$ were computed by DFT method considering the weighting of all possible pathways (Table S17). (b) Relaxed potential energy scans of thermal $Z \rightarrow E$ isomerization for azobispyrazoles (taking 3-3 as an example) obtained by DFT method. (c) $\mathrm{NCI}$ surfaces of the predominant $Z$-isomers and transition states for azobispyrazoles in DMSO (isosurface value of 0.6). The greener and redder areas represent dispersion attractions and steric repulsion, respectively.

For the other three molecules (4-4, 3-4 and 3-3), their Z-isomers displayed similar NCI surfaces, but there was a difference in the intramolecular interactions for their TS geometries. TSs of 4-4 and 3-4 were stabilized by a pure $\mathrm{C}-\mathrm{H} \cdots \mathrm{H}-\mathrm{C}$ dispersive interaction, whereas 3-3 showed $\mathrm{C}-\mathrm{H} \cdots \mathrm{N}$ interaction (somewhat electrostatic) because the $\mathrm{C}-\mathrm{H}$ group oriented to the pyridine-type $\mathrm{N}$ atom (instead of $\mathrm{C}-\mathrm{H}$ group) on the opposite ring. The latter interaction could more effectively reduce energy barrier, making Z-3-3 less stable than the other two. The slight shorter $t_{1 / 2}$ of 3-4 than that of 4-4 was presumably because this $\mathrm{C}-\mathrm{H} \cdots \mathrm{N}$ interaction could be also found in non-predominant TS conformers for 3-4.

Based on the analysis above, the dependence of $t_{1 / 2}$ on linkage pattern could be roughly understood by 
the different groups ortho to azo-bridge that gave different stabilizing interactions in TSs. In specific, ortho $\mathrm{C}-\mathrm{H}$ group on 4-pyrazole only afforded $\mathrm{C}-\mathrm{H} \cdots \mathrm{H}-\mathrm{C}$ dispersive interaction, and ortho $\mathrm{N}$ lone pair on 3-pyrazole could add some electrostatic attraction, while the bulky ortho $\mathrm{N}$-Methyl on 5-pyrazole could give rise to the largest intramolecular stabilizing interactions.

\section{Conclusions}

In conclusion, we have designed and investigated a family of azobispyrazoles as new bis-heteroaryl photoswitches. A facile synthetic route is established for constructing azopyrazoles free of substituents ortho to azo group. All the six azobispyrazoles show excellent bidirectional $E \leftrightarrows Z$ photoconversions, and their $Z$-isomer $t_{1 / 2}$ cover a wide timescale including years, months, weeks, days, and hours. Azobispyrazole system bearing 5-pyrazole moiety shows higher $\pi$-conjugation, so the $\pi$ - $\pi^{*} \lambda_{\max }$ of $E$ isomer follows the order of 5-5 $>\mathbf{3}(\mathbf{4})-\mathbf{5}>\mathbf{3}(\mathbf{4})-\mathbf{3}(\mathbf{4})$. $5-5$ can be used as a bidirectionally visible-lightactivated photoswitch with a $t_{1 / 2}$ of $7 \mathrm{~h}$ (the longest $t_{1 / 2}$ for visible light bis-heteroaryl azo switches reported so far). The linkage pattern also directs the thermal back-isomerization kinetics, with $t_{1 / 2}$ following the order of 4-4 $>$ 3-4 $>$ 3-3 $>$ 4-5 $>$ 3-5 $>$ 5-5. This can be explained by the different intramolecular stabilizing interactions brought by 4-, 3-, 5-pyrazolyl moieties in TSs as well as Z-isomers. Different with phenylazopyrazoles, where the T-shaped conformation of $Z$-isomer dictates ultralong $t_{1 / 2}$ while hinders $Z \rightarrow E$ photoconversion, the twisted $Z$-isomer of azobispyrazoles can furnish both ultralong and short $t_{1 / 2}$ without compromising the backing photoswitching efficiency. The combination of (near-)quantitative bidirectionality and widely tunable $t_{1 / 2}$ makes azobispyrazoles advantageous over most heteroaryl azo switches reported so far. Therefore, azobispyrazoles show great potential in developing high-performance photocontrollable systems and can inspire the rational design of new photoswitches making use of Het-N=N-Het architecture. 


\section{Supporting Information}

Synthesis, characterization, methods, and computational details, including Figures S1-S31 and Tables S1-S17.

\section{Acknowledgments}

This work was supported by the National Key Research and Development Program of China (2017YFA0207500), National Natural Science Foundation of China (22022507, 51973111), Shanghai Science and Technology Committee (17ZR1447300), Beijing National Laboratory for Molecular Sciences (BNLMS202004) and China Postdoctoral Science Foundation (2020M681279). We acknowledge the single-crystal XRD analysis support by Dr. Lingling Li from the Instrumental Analysis Center of Shanghai Jiao Tong University.

\section{References}

(1) Szymański, W.; Beierle, J. M.; Kistemaker, H. A. V.; Velema, W. A.; Feringa, B. L. Reversible Photocontrol of Biological Systems by the Incorporation of Molecular Photoswitches. Chem. Rev. 2013, 113, $6114-6178$.

(2) Glusac, K. What has light ever done for chemistry? Nat. Chem. 2016, 8, $734-735$.

(3) Baroncini, M.; Silvi, S.; Credi, A. Photo- and Redox-Driven Artificial Molecular Motors. Chem. Rev. 2020, $120,200-268$.

(4) Kathan, M.; Hecht, S. Photoswitchable Molecules as Key Ingredients to Drive Systems Away From the Global Thermodynamic Minimum. Chem. Soc. Rev. 2017, 46, 5536 - 5550.

(5) Zhang, J.; Zou, Q.; Tian, H. Photochromic Materials: More Than Meets the Eye. Adv. Mater. 2013, 25, 378 399.

(6) Huang, X.; Li, T. Recent Progress in the Development of Molecular-Scale Electronics Based on Photoswitchable Molecules. J. Mater. Chem. C 2020, 8, 821 - 848.

(7) Goulet-Hanssens, A.; Eisenreich, F.; Hecht, S. Enlightening Materials with Photoswitches. Adv. Mater. 2020, 32, 1905966.

(8) Wang, L.; Li, Q. Photochromism into Nanosystems: Towards Lighting Up the Future Nanoworld. Chem. Soc. Rev. 2018, 47, $1044-1097$.

(9) Sun, C.; Wang, C.; Boulatov, R. Applications of Photoswitches in the Storage of Solar Energy. ChemPhotoChem 2019, 3, 268 - 283.

(10) Gelebart, A. H.; Jan Mulder, D.; Varga, M.; Konya, A.; Vantomme, G.; Meijer, E. W.; Selinger, R. L. B.; Broer, D. J. Making Waves in a Photoactive Polymer Film. Nature 2017, 546, 632 - 636.

(11) Ube, T.; Ikeda, T. Photomobile Polymer Materials with Crosslinked Liquid-Crystalline Structures: Molecular Design, Fabrication, and Functions. Angew. Chem. Int. Ed. 2014, 53, 10290 - 10299.

(12) Riefolo, F.; Matera, C.; Garrido-Charles, A.; Gomila, A. M. J.; Sortino, R.; Agnetta, L.; Claro, E.; Masgrau, R.; Holzgrabe, U.; Batlle, M.et al. Optical Control of Cardiac Function with a Photoswitchable Muscarinic Agonist. J. Am. Chem. Soc. 2019, 141, 7628 - 7636.

(13) Broichhagen, J.; Frank, J. A.; Trauner, D. A Roadmap to Success in Photopharmacology. Accounts Chem. Res. 2015, 48, $1947-1960$.

(14) Dong, L.; Feng, Y.; Wang, L.; Feng, W. Azobenzene-Based Solar Thermal Fuels: Design, Properties, and Applications. Chem. Soc. Rev. 2018, 47, $7339-7368$. 
(15) Wu, S.; Butt, H. J. Solar-Thermal Energy Conversion and Storage Using Photoresponsive AzobenzeneContaining Polymers. Macromol. Rapid Comm. 2020, 41, 1900413.

(16) Zhang, Z.; He, Y.; Wang, Z.; Xu, J.; Xie, M.; Tao, P.; Ji, D.; Moth-Poulsen, K.; Li, T. Photochemical Phase Transitions Enable Coharvesting of Photon Energy and Ambient Heat for Energetic Molecular Solar Thermal Batteries That Upgrade Thermal Energy. J. Am. Chem. Soc. 2020, 142, 12256 - 12264.

(17) Mart, R. J.; Allemann, R. K. Azobenzene Photocontrol of Peptides and Proteins. Chem. Commun. 2016, 52, $12262-12277$

(18) Lin, W.; Tsai, M.; Rajappa, R.; Kramer, R. H. Design of a Highly Bistable Photoswitchable Tethered Ligand for Rapid and Sustained Manipulation of Neurotransmission. J. Am. Chem. Soc. 2018, 140, 7445 - 7448.

(19) Hvilsted, S.; Sánchez, C.; Alcalá, R. The Volume Holographic Optical Storage Potential in Azobenzene Containing Polymers. J. Mater. Chem. 2009, 19, $6641-6648$.

(20) Hartley, G. S. The Cis-form of Azobenzene. Nature 1937, 140, 281.

(21) Merino, E. Synthesis of Azobenzenes: the Coloured Pieces of Molecular Materials. Chem. Soc. Rev. 2011, 40, $3835-3853$.

(22) Bandara, H. M. D.; Burdette, S. C. Photoisomerization in Different Classes of Azobenzene. Chem. Soc. Rev. 2012, 41, 1809 - 1825.

(23) Crespi, S.; Simeth, N. A.; König, B. Heteroaryl Azo Dyes as Molecular Photoswitches. Nature Reviews Chemistry 2019, 3, $133-146$.

(24) Wang, Y.; Ge, X.; Schull, G.; Berndt, R.; Tang, H.; Bornholdt, C.; Koehler, F.; Herges, R. Switching Single Azopyridine Supramolecules in Ordered Arrays on Au(111). J. Am. Chem. Soc. 2010, 132, 1196 - 1197.

(25) Venkataramani, S.; Jana, U.; Dommaschk, M.; Sönnichsen, F. D.; Tuczek, F.; Herges, R. Magnetic Bistability of Molecules in Homogeneous Solution at Room Temperature. Science 2011, 331, 445.

(26) Procházková, E.; Čechová, L.; Kind, J.; Janeba, Z.; Thiele, C. M.; Dračínský, M. Photoswitchable Intramolecular Hydrogen Bonds in 5-Phenylazopyrimidines Revealed By In Situ Irradiation NMR Spectroscopy. Chem. Eur. J. 2018, 24, $492-498$.

(27) Xu, Y.; Gao, C.; Andréasson, J.; Grøtli, M. Synthesis and Photophysical Characterization of Azoheteroarenes. Org. Lett. 2018, 20, $4875-4879$.

(28) Otsuki, J.; Suwa, K.; Sarker, K. K.; Sinha, C. Photoisomerization and Thermal Isomerization of Arylazoimidazoles. J. Phys. Chem. A 2007, 111, 1403 - 409.

(29) Wendler, T.; Schütt, C.; Näther, C.; Herges, R. Photoswitchable Azoheterocycles via Coupling of Lithiated Imidazoles with Benzenediazonium Salts. J. Org. Chem. 2012, 77, 3284 - 3287.

(30) Weston, C. E.; Richardson, R. D.; Haycock, P. R.; White, A. J. P.; Fuchter, M. J. Arylazopyrazoles: Azoheteroarene Photoswitches Offering Quantitative Isomerization and Long Thermal Half-Lives. J. Am. Chem. Soc. 2014, 136, $11878-11881$.

(31) Calbo, J.; Weston, C. E.; White, A. J. P.; Rzepa, H. S.; Contreras-García, J.; Fuchter, M. J. Tuning Azoheteroarene Photoswitch Performance through Heteroaryl Design. J. Am. Chem. Soc. 2017, 139, 1261 1274.

(32) Slavov, C.; Yang, C.; Heindl, A. H.; Wegner, H. A.; Dreuw, A.; Wachtveitl, J. Thiophenylazobenzene: An Alternative Photoisomerization Controlled by Lone-Pair $\cdots \pi$ Interaction. Angew. Chem. Int. Ed. 2020, 59, 380 $-387$.

(33) Heindl, A. H.; Wegner, H. A. Rational Design of Azothiophenes-Substitution Effects on the Switching Properties. Chem. Eur. J. 2020, 26, $13730-13737$.

(34) Kumar, P.; Srivastava, A.; Sah, C.; Devi, S.; Venkataramani, S. Arylazo-3,5-dimethylisoxazoles: Azoheteroarene Photoswitches Exhibiting High Z-Isomer Stability, Solid-State Photochromism, and Reversible Light-Induced Phase Transition. Chem. Eur. J. 2019, 25, 11924 - 11932. 
(35) Devi, S.; Saraswat, M.; Grewal, S.; Venkataramani, S. Evaluation of Substituent Effect in Z-Isomer Stability of Arylazo-1H-3,5-dimethylpyrazoles: Interplay of Steric, Electronic Effects and Hydrogen Bonding. J. Org. Chem. 2018, 83, $4307-4322$.

(36) Stricker, L.; Böckmann, M.; Kirse, T. M.; Doltsinis, N. L.; Ravoo, B. J. Arylazopyrazole Photoswitches in Aqueous Solution: Substituent Effects, Photophysical Properties, and Host-Guest Chemistry. Chem. Eur. J. 2018, 24, $8639-8647$.

(37) Zhang, Z. Y.; He, Y.; Zhou, Y.; Yu, C.; Han, L.; Li, T. Pyrazolylazophenyl Ether-Based Photoswitches: Facile Synthesis, (Near-)Quantitative Photoconversion, Long Thermal Half-Life, Easy Functionalization, and Versatile Applications in Light-Responsive Systems. Chem. Eur. J. 2019, 25, 13402 - 13410.

(38) Simeth, N. A.; Crespi, S.; Fagnoni, M.; König, B. Tuning the Thermal Isomerization of Phenylazoindole Photoswitches from Days to Nanoseconds. J. Am. Chem. Soc. 2018, 140, 2940 - 2946.

(39) Travieso-Puente, R.; Budzak, S.; Chen, J.; Stacko, P.; Jastrzebski, J. T. B. H.; Jacquemin, D.; Otten, E. Arylazoindazole Photoswitches: Facile Synthesis and Functionalization via SNAr Substitution. J. Am. Chem. Soc. 2017, 139, $3328-3331$.

(40) Kolarski, D.; Szymanski, W.; Feringa, B. L. Two-Step, One-Pot Synthesis of Visible-Light-Responsive 6Azopurines. Org. Lett. 2017, 19, 5090 - 5093.

(41) Weston, C. E.; Richardson, R. D.; Fuchter, M. J. Photoswitchable Basicity through the Use of Azoheteroarenes. Chem. Commun. 2016, 52, 4521 - 4524.

(42) Kennedy, A. D. W.; Sandler, I.; Andréasson, J.; Ho, J.; Beves, J. E. Visible-Light Photoswitching by Azobenzazoles. Chem. Eur. J. 2020, 26, 1103 - 1110.

(43) Huddleston, P. R.; Volkov, V. V.; Perry, C. C. The Structural and Electronic Properties of 3,3'-Azothiophene Photo-Switching Systems. Phys. Chem. Chem. Phys. 2019, 21, $1344-1353$.

(44) Garcia-Amorós, J.; R. Castro, M. C.; Coelho, P.; M. Raposo, M. M.; Velasco, D. New Heterocyclic Systems to Afford Microsecond Green-Light Isomerisable Azo Dyes and Their Use as Fast Molecular Photochromic Switches. Chem. Commun. 2013, 49, 11427 - 11429.

(45) Coelho, P. J.; Castro, M. C. R.; Fernandes, S. S. M.; Fonseca, A. M. C.; Raposo, M. M. M. Enhancement of the Photochromic Switching Speed of Bithiophene Azo Dyes. Tetrahedron Lett. 2012, 53, 4502 - 4506.

(46) Coelho, P. J.; Castro, M. C. R.; Fonseca, A. M. C.; Raposo, M. M. M. Photoswitching in Azo Dyes Bearing Thienylpyrrole and Benzothiazole Heterocyclic Systems. Dyes Pigm. 2012, 92, 745 - 748.

(47) Raposo, M. M. M.; Fonseca, A. M. C.; Castro, M. C. R.; Belsley, M.; Cardoso, M. F. S.; Carvalho, L. M.; Coelho, P. J. Synthesis and Characterization of Novel Diazenes Bearing Pyrrole, Thiophene and Thiazole Heterocycles as Efficient Photochromic and Nonlinear Optical (NLO) Materials. Dyes Pigm. 2011, 91, 62 73.

(48) Patel, H. V.; Vyas, K. A.; Pandey, S. P.; Fernandes, P. S. Reaction of 2, 3, 4-pentantrione-3-arylhydrazones with $N, \mathrm{~N}$-dimethylhydrazine: Formation of substituted $1 \mathrm{H}$-pyrazoles via demethylation. Synthetic Commun. 1992, 22, $3081-3087$.

(49) Trivella, A.; Coussan, S.; Chiavassa, T. Malonaldehyde Synthesis. Synthetic Commun. 2008, 38,3285 - 3290.

(50) López-Tarifa, P.; Sánchez-Sanz, G.; Alkorta, I.; Elguero, J.; Sanz, D.; Perona, A.; Claramunt, R. M. The Tautomeric Structures of 3(5),3'(5')-Azopyrazole [(E)-1,2-di(1H-pyrazol-3(5)-yl)diazene)]: The Combined Use of NMR and Electronic Spectroscopies with DFT Calculations. J. Mol. Struct. 2012, 1015, 138 - 146.

(51) Rustler, K.; Nitschke, P.; Zahnbrecher, S.; Zach, J.; Crespi, S.; König, B. Photochromic Evaluation of 3(5)Arylazo-1H-pyrazoles. J. Org. Chem. 2020, 85, $4079-4088$.

(52) Lyalin, B. V.; Sigacheva, V. L.; Kokorekin, V. A.; Dutova, T. Y.; Rodionov, G. M.; Petrosyan, V. A. Oxidative Transformation of $\mathrm{N}$-Substituted 3-Aminopyrazoles to Azopyrazoles Using Electrogenerated Bromine as A Mediator. Russ. Chem. B.+ 2018, 67, $510-516$. 
(53) Lyalin, B. V.; Sigacheva, V. L.; Kokorekin, V. A.; Petrosyan, V. A. Electrosynthesis of Azopyrazoles via the Oxidation of $\mathrm{N}$-alkylaminopyrazoles on a $\mathrm{NiO}(\mathrm{OH})$ Anode in Aqueous Alkali - A Green Method for N-N Homocoupling. Tetrahedron Lett. 2018, 59, 2741 - 2744.

(54) Bredas, J. Mind the Gap! Mater. Horizons 2014, 1, 17 - 19.

(55) Martin, R. L. Natural Transition Orbitals. J. Chem. Phys. 2003, 118, 4775 - 4777.

(56) Lu, T.; Chen, F. Multiwfn: a Multifunctional Wavefunction Analyzer. J. Comput. Chem. 2012, 33, 580 - 592.

(57) Bléger, D.; Schwarz, J.; Brouwer, A. M.; Hecht, S. o-Fluoroazobenzenes as Readily Synthesized Photoswitches Offering Nearly Quantitative Two-Way Isomerization with Visible Light. J. Am. Chem. Soc. 2012, 134, $20597-20600$.

(58) Calbo, J.; Thawani, A. R.; Gibson, R. S. L.; White, A. J. P.; Fuchter, M. J. A Combinatorial Approach to Improving the Performance of Azoarene Photoswitches. Beilstein J. Org. Chem. 2019, 15, 2753 - 2764.

(59) Johnson, E. R.; Keinan, S.; Mori-Sánchez, P.; Contreras-García, J.; Cohen, A. J.; Yang, W. Revealing Noncovalent Interactions. J. Am. Chem. Soc. 2010, 132, 6498 - 6506. 